\title{
Corporate social responsibility and competitive advantage: Overcoming the trust barrier
}

Shuili Du, Simmons College

C. B. Bhattacharya, ESMT

Sankar Sen, Baruch College, City University of New York 


\title{
Abstract
}

\section{Corporate social responsibility and competitive advantage: Overcoming the trust barrier}

\author{
Author(s):* Shuili Du, Simmons College \\ C. B. Bhattacharya, ESMT \\ Sankar Sen, Baruch College, City University of New York
}

This research builds on the complementary corporate social responsibility (CSR) literatures in strategy and marketing to provide insight into the efficacy of CSR as a challenger's competitive weapon against a market leader. Through an investigation of a real world CSR initiative, we show that the challenger can reap superior business returns among consumers who had participated in its CSR initiative, relative to those who were merely aware of the initiative. Specifically, participant consumers demonstrate the desired attitudinal and behavioral changes in favor of the challenger, regardless of their affective trust in the leader, whereas aware consumers' reactions become less favorable as their affective trust in the leader increases. Furthermore, participation, unlike mere awareness, transforms the nature of the consumer-challenger relationship from a transactional one to a communal, trust-based one.

Keywords: corporate social responsibility, competitive strategy, challenger brand, affective trust 
Today, corporate social responsibility (CSR), a firm's commitment to maximize long-term economic, societal and environmental well being through business practices, policies and resources, is a strategic imperative. Spurred by the thinking of leading strategy, management and marketing scholars (e.g., Kotler and Lee 2005; Lemon, Roberts, Winer, and Raghubir 2010; Mahoney, McGahan, and Pitelis 2009; Margolis and Walsh 2003; Porter and Kramer 2006), most forward-thinking firms across the globe are approaching CSR as not merely their ethical responsibility to society and the environment, but instead a way to achieve their strategic objectives while at the same time bettering the world (i.e., creating joint value for the firm and society). In line with this emerging perspective, more and more companies are engaging in initiatives that try to improve public health, safety, the environment or community well being through the active participation of key stakeholder groups such as consumers. Kotler and Lee (2005) call such initiatives corporate social marketing initiatives, labeling them 'best of breed' among alternative corporate social initiatives in terms of their ability to improve consumer well being while at the same time helping achieve strategic goals such as market development and increased sales. For example, the personal care brand Dove, in partnership with the Girl Scouts, has an initiative aimed at a critical social issue facing its consumers and their families: pervasive low self-esteem among adolescent and pre-adolescent girls, with accompanying risky behaviors such as smoking, eating disorders, and suicidal tendencies (Unilever 2010; Girl Scouts 2010). This program, which comprises age-appropriate curricula and workshops that inspire girls - also Dove consumers - to embrace a wider definition of beauty, build a strong sense of self, and take care of their bodies and minds, has greatly boosted the popularity and sales of Dove products (Cone and Darigan 2010).

An important strategic objective for many firms/brands ${ }^{1}$ is to gain a competitive advantage over their often formidable rivals. Thus, it is not surprising that a recent large scale study of CFO's, investment professionals, CSR managers (McKinsey Quarterly 2009) revealed that "strengthening competitive position" is a key impetus for firms to engage in strategic CSR. Yet, even as the debate on CSR has shifted decisively from "whether" to "how" (Smith 2003), there exists little conceptual clarity regarding when, how and why firms might be able to achieve their strategic goals, such as gaining a competitive advantage, through their CSR actions. This is due in part to the disparate perspectives the different 
disciplines have brought to their examination of strategic CSR. Researchers in management (encompassing strategy and organizational behavior) have typically focused on macro and meso level issues such as the link between CSR and firm financial performance (e.g., Godfrey, Merrill and Hansen 2009; Margolis and Walsh 2003), finding such a link to, notably, be positive but equivocal. In contrast, marketing researchers have adopted a markedly micro-level perspective to understand when, why and how consumers respond positively to CSR, engaging in pro-brand behaviors (e.g., $\mathrm{Du}$, Sen and Bhattacharya 2008; Sen and Bhattacharya 2001). Consequently, while the notion that CSR can lead to competitive advantage is implicit to current thought in management, there is scant insight into the actual consumer-level dynamics underlying a company's ability to use CSR as a strategic competitive lever. Conversely, while marketing has focused on the when, why and how of customer reactions, extant CSR work in this discipline has focused on single firm/brand contexts (e.g., Sen, Bhattacharya and Korschun 2006; Simmons and Becker-Olsen 2006), neglecting the role of competition in the strategic returns to CSR.

This paper aims to understand the conditions under which a brand's CSR actions can serve as effective instruments of competitive strategy, helping it compete with a formidable market leader. A basic premise of this research is that the success of such a macro-level strategic objective depends, ultimately, on the micro-level actions of individual consumers. Thus, we take an individual-level consumer psychology perspective to investigate the efficacy of an actual, real-world CSR initiative in helping a brand strengthen its competitive position. In doing so, this research attempts to span, integratively, the disparate perspectives on CSR, ranging from strategy (i.e., management) to consumer behavior (i.e., marketing).

The results of a qualitative focus group study and a field survey involving the target consumers of a challenger's CSR initiative reveal that its efficacy in helping the challenger gain customers from the market leader (i.e., its primary competitor) hinges, interactively, on two key factors: consumers' participation in (vs. awareness of) the initiative and their affective trust in both the challenger (i.e., their perceptions of the company's care and concern for its consumers) and the leader. These findings contribute to the literatures of marketing, strategy, and CSR in several ways. First, they demonstrate the 
superior business returns, in terms of attitudinal and behavioral outcomes, among consumers who have participated in and tangibly benefitted from a brand's CSR initiative relative to those who are merely aware of the initiative. This finding comprises the first micro-level empirical affirmation for the notion of strategic CSR articulated by both marketing (e.g., Kotler and Lee 2005) and strategy (e.g., Porter and Kramer 2006) scholars; the strategic superiority of a program that requires consumer participation (e.g., a corporate social marketing initiative) stems from its ability to not only wean consumers off their existing loyalty to a competitor but also, as our results show, transform their relationship with the brand from a short-term, transactional nature to a communal, trust-driven nature.

Second, we show that the reactions of aware consumers to a brand's CSR initiative can range in favorability depending on the strength of their existing relationship with its competitor. This finding underscores the critical influence of the competitive dynamics in the marketplace, a factor largely neglected in the extant CSR research. At the same time, our research contributes to the persuasion literature (e.g., Ahluwalia 2000) by demonstrating that direct participation in a CSR initiative, if a positive experience, can overcome the biasing influence of strong attitudes (i.e., those towards the leader) in consumers' processing of counter-attitudinal information (i.e., favorable CSR information about the challenger).

Third, our findings highlight the pivotal but thus far unexamined role of affective brand trust at the individual consumer level in driving the strategic returns to CSR. Our findings show that participation in a challenger's CSR initiative transforms consumer-brand relationships by engendering affective trust in the challenger, which then converts consumers into brand champions. As well, we show that, affective trust in the rival market leader captures, importantly, the strength of the consumer - leader relationship, representing the competitive barrier the challenger must overcome in order to win consumers over from the leader. In other words, we add to the strategy and marketing literatures by identifying trust in the focal brand's competitor as a moderator of CSR's efficacy as an instrument of competition.

Finally, our research demonstrates that through CSR programs that entail consumer participation, a challenger brand can go beyond the standard marketing mix to appeal directly to consumers' hearts, thus reshaping the competitive game with the leader. This finding is significant in light of the extant literature 
on the pioneer/leader vs. challenger competition, which suggests that the challenger is at a significant disadvantage if it chooses to compete against a leader on marketing mix variables (e.g., product attributes, price; Bowman and Gatignon 1996).

The rest of the paper is organized as follows. We first describe the empirical context of our research. We then report two studies, a qualitative one that, together with relevant literatures, informs our conceptualization about consumer reactions to a brand's CSR initiative in a competitive marketplace, and a quantitative field study to test our predictions. We end with a discussion on the implications of our findings for theory and practice, as well as areas of future research.

\section{Empirical Context: A Corporate Oral Health Initiative}

A strategic approach to CSR requires a company to address social issues that intersect with its particular business, such as important concerns of its consumers (Kotler and Lee 2005; Porter and Kramer 2006). For producers of oral care products, a relevant, serious social issue facing many of their consumers is the existence of "a silent epidemic": widespread dental and oral diseases in disadvantaged communities, especially among children of minority racial/ethnic groups (Fisher-Owens et al. 2008; Lewit and Kerrebrock 1998; U.S. Department of Health and Human Services 2000). Oral diseases cause significant pain, poor appearance, and valuable time lost from school (e.g., more than 51 million school hours are lost every year due to illnesses related to oral health, Center for Disease Control and Prevention 2009) — problems that can greatly diminish a child's self-image, welfare, and chances of future success. The Surgeon General's report: Oral Health in America (U.S. Department of Health and Human Services 2000) in 2000 explicitly called upon different sectors such as private industry, nonprofit organizations, and health professionals to take action to solve this public health issue.

As an answer to this call for action, a major brand of oral care products launched a national outreach program in the year 2000 that, in partnership with the Boys and Girls Club of America (BGCA), the American Dental Association, and dental schools across the country, provides oral health education, dental care tools and services to children and their families in economically disadvantaged communities 
nationwide (Kotler and Lee 2004) ${ }^{2}$. At the core of this initiative is a four million dollar per year oral health program created in partnership with BGCA, a national network of 3,300 neighborhood-based recreational/educational facilities (called clubs) for economically disadvantaged children. The oral health program has an age-appropriate oral hygiene curriculum in which participants learn about proper oral health through videos, audio-tapes, a web site, and interactive lesson plans. All participating children also receive oral care tools (e.g., toothbrushes, toothpaste, and dental floss) and parent brochures to take home. In addition, the oral care brand has built full service dental clinics in select BGCA clubs across the country to provide low cost oral care, including screening and treatment.

Notably, we learnt from our initial interviews with brand managers that a key business objective of this initiative was to gain a foothold in the U.S. Hispanic market, which, while an important strategic market segment due to their large size and rapid growth, was overwhelmingly loyal to the brand's primary competitor, the market leader. In other words, in addition to the social goal of addressing a critical public health problem facing its consumers, this initiative also had the strategic business goal of gaining consumers from the market leader.

\section{Qualitative Study}

\section{Method}

Design. We conducted 6 focus groups $(8-10$ respondents each) in three different urban areas with large Hispanic populations. We did two focus groups in each area, one with parents of Hispanic children that had participated in the oral health initiative (i.e., participant consumers), and one with parents of Hispanic children that had not participated (i.e., non-participant consumers). We focused on parents for three related reasons. First, this was consistent with our conceptualization of the program participant as the family rather than just the children (Lackman and Lanassa 1993). The program relied on the physical and psychological participation of not just the children but the parents as well (e.g., it was the parents who enrolled their children in the program). In that sense, program participation, like many other conventional consumption activities, was engaged in not individually but as a group. Second, parents are more able to 
evaluate the efficacy of the program in terms of changes in their children's oral health behaviors and psychosocial well being. Third, parents are the primary decision makers and purchasers of oral care products and hence are in the best position to talk about their beliefs of oral care brands. Finally, we chose to focus on Hispanic consumers because Hispanics are one of the primary targets of this program (another primary target being African Americans), and because the Hispanic market segment is of particular strategic value to the challenger.

Participant consumers were screened on the following criteria: (1) self-identified Hispanic race, (2) 18 to 45-year-old, (3) with child(ren) who have either completed or are close to completing the oral care program, and (4) the primary caretaker of the child(ren) and the decision maker for their out-of-school activities. Non-participants consisted of Hispanic parents from the same neighborhoods whose children had not participated (i.e., none of the children had ever participated) in the program. Only four participants were male; the rest were female. Each was paid $\$ 100$ for his/her participation.

Procedure. The focus groups were conducted in Spanish by a Hispanic moderator from a qualitative research company that specializes in Hispanic communities. The moderator began with general questions about the level and importance of oral hygiene in their families. Then respondents talked about their purchase behaviors and beliefs of oral care products, mostly toothpaste and toothbrush. Not surprisingly, the brand behind the oral health initiative and its major competitor (i.e., the challenger and the leader), emerged as the predominant brands used by nearly all respondents. Respondents then did a brand imagery exercise describing these two brands as if they were human beings. Finally, respondents talked about the challenger's oral health initiative. Due to the non-participant consumers' low awareness of the program (only two had heard of it), this group watched a short video about the program before talking about their reactions. All focus group discussions were videotaped, translated into English, and transcribed.

QSR NVIVO, a leading software for qualitative data analysis, was used to code, manage, and explore the transcripts. Analysis followed an iterative approach, traveling back and forth between the data and the emerging theory (Eisenhardt 1989). We judged the trustworthiness of focus group findings by triangulation of multiple quotes from participants in different focus groups and interpreted these findings in light of relevant literatures. 


\section{Findings}

Competitive status: challenger vs. leader brand. Consistent with the information provided by the challenger's brand managers, the focus group discussion revealed that its key competitor is the incumbent brand and leader in the U.S. Hispanic market ${ }^{3}$. The leader's dominance derives primarily from the fact that it entered most Hispanic markets before the challenger and has remained very popular in these markets ever since. Consequently, even after migration to the U.S., the focal Hispanic consumers continue to use the brand they have grown up with. As both Participant and Non-participant Consumers commented, "In Mexico, the most popular toothpaste is [the leader]. That is what we are used to." "I remember that years ago in Monterrey the first toothpaste that came out was [the leader] and years later [the challenger] came out. People were afraid to change; you got accustomed to [the leader].”

Reactions of Participant consumers. One prominent finding from the focus group discussions is that participation in the challenger's initiative had enhanced consumers' trust in the challenger. When asked to describe the two brands as if they were human beings, an exercise intended to reveal consumers' brand associations, non-participant consumers, largely unaware of the initiative, described the challenger as "feminine, gentle, younger, not as famous as the leader," and the leader as "masculine, strong, professional, aggressive, experienced, successful." Participant consumers shared many of these brand associations, but importantly, also described the challenger as "caring, trustworthy, angelical, and Latino (it is one of us)." Notably, these descriptors brought up only by participant consumers reflected their greater affective trust in the challenger (ATC), which are associations pertaining to how much a brand cares about consumers' welfare (Chua, Ingram, and Morris 2008; Doney and Cannon 1997; McAllister 1995). On the other hand, participant consumers still shared non-participant consumers' associations relating to the challenger's expertise and capability (i.e., cognitive trust; Doney and Cannon 1997; McAllister 1995), as indicated by descriptors of the challenger "younger, not as famous," and those of the leader "professional, experienced, and successful." Collectively, the group comparison revealed differences in ATC but not cognitive trust in the challenger.

Furthermore, in the social psychology literature, trustworthiness (i.e., a person's likelihood to make 
good faith contributions to benefit the collective well-being of a relationship, a notion similar to affective trust in the marketing literature) has been shown to be the single most important characteristic for ideal members of interdependent groups (e.g., work teams) and relationships (e.g., friends, family members; Cottrell, Neuberg, and Li 2007; Rempel, Holmes, and Zanna 1985). To further assess changes in participant consumers' ATC, we asked a series of choice questions on the challenger and the leader's suitability for several interdependent social relations (i.e., whom they would choose to be friends with, whom they would leave their children with, and whom they would choose as a business partner). Consistent with their greater ATC, most participant consumers chose the challenger while most non-participant consumers chose the leader in these scenarios. Together, these differences between participant and non-participant consumers suggest that participation in the initiative has fostered greater ATC as well as greater willingness to enter into a communal, interdependent relationship with the challenger. In the words of one participant consumer, "They worry about us. Economically it is expensive but they give it for free. You invest in a company but the company is also serving you."

This finding that participation in the challenger's initiative enhances ATC but not cognitive trust is in line with the trust literature, which distinguishes between affective and cognitive trust and has identified distinct antecedents to these two types of trust. While cognitive trust, pertaining to a brand's perceived expertise and capability, will likely be driven by calculative and instrumental assessments such as product performance, firm size, and market position (Chua et al. 2008; Doney and Cannon 1997; McAllister 1995), affective trust, pertaining to beliefs of how much a brand is genuinely interested in consumers' welfare, will likely be driven by behaviors that indicate care and concern for the consumers, such as CSR initiatives. Further, cognitive trust is short-term and exchange-oriented in nature, while affective trust fosters communal and long-term relationships (Chua et al. 2008; McAllister 1995; Rousseau et al. 1999).

In addition to participant consumers' greater ATC relative to non-participant consumers, there were clear differences in the pro-challenger behaviors between the two groups. For instance, while only a few of the non-participant consumers said they ever bought the challenger's toothpaste, roughly $50 \%$ of the participant consumers reported buying it frequently. Also importantly, participant consumers mentioned that because "it is a company that helps the community," they had supported or would support the 
challenger through not just purchase but also a broader set of behaviors such as recommending the brand to friends, talking about the oral health initiative, and volunteering for the brand.

Reactions of aware consumers: the moderating role of affective trust in leader (ATL). Since only two consumers in our non-participant focus groups had heard of the challenger's initiative, we created awareness by showing all non-participants a 5-minute video of the initiative. Interestingly, unlike participant consumers, who seemed to have universally embraced the initiative, the reactions of the aware consumers to the initiative varied dramatically with the strength of their extant relationship with the leader. Although most aware consumers purchased the leader frequently, the focus groups revealed that their relationship with the leader ranged from a passive inertia to a strong affective bond. Aware consumers who were not strongly attached to the leader eagerly embraced the CSR initiative and applauded the challenger's efforts to help their community. For instance, one aware consumer who always patronized the leader because "I'm used to it," commented, "I have bought [the challenger] before because my son likes the taste and packaging but I hadn't given it much thought. Now I think I am even going to buy it for myself. I have never seen [the leader] do something like this to help kids.”

In contrast, aware consumers who were emotionally attached to the leader tended to resist the initiative, with some questioning the sincerity of the challenger's motives, and others arguing that the leader provided similar benefits to the community. One aware consumer who described the leader as trustworthy (i.e., "supportive and warmhearted") was suspicious of the challenger's motive, "They (the challenger) help the community to make a name for themselves and to gain popularity." Another aware consumer defended the leader thus: "[The leader] has lots of health fairs. They had vans with doctors providing free checkups and they also gave information about clinics where you could get treatment.”

This pattern of reactions is not entirely surprising in light of research in the consumer psychology literature that documents resistance to counter-attitudinal information among individuals with strongly held attitudes (Ahluwalia 2000; Ahluwalia, Burnkrant, and Unnava 2000; Eagly and Chaiken 1995). For example, Ahluwalia et al. (2000) find that consumers' commitment toward a brand moderates their response to negative publicity in that high-commitment consumers actively counter-argue against negative information and resist attitude change, whereas low-commitment consumers process the negative 
information objectively. It is worth noting, however, that in contrast to prior research, which examines consumer reactions to negative information about a focal brand (e.g., Ahluwalia et al. 2000), our respondents display similar resistance but to even positive information about a competing brand. In other words, affective trust in the leader (ATL) emerged from the focus groups to be the key attitudinal variable affecting aware consumers' reactions to the challenger's initiative. Aware consumers with high ATL tried to discount the challenger's initiative (e.g., inferring self-serving motives, such as "to make a name for themselves."), while those with low ATL seemed to process the information in a more objective manner, viewing the initiative as an indicator of the challenger's trustworthiness (e.g., inferring more intrinsic motives, such as "this means they [challenger] care about our welfare and want us to get ahead"). Not surprisingly then, aware consumers with low ATL exhibited greater attitudinal and behavioral change in favor of the challenger (e.g., "I am going to buy it") compared to those with high ATL. This moderating effect of ATL points to the power of strong consumer-brand relationships in warding off competitive attacks (Fournier 1998); from the challenger's perspective, ATL signifies the competitive barrier that the brand needs to overcome in gaining favor with the aware consumers.

Perhaps the most intriguing finding from the focus groups is that, contrary to what the extant literature on persuasion resistance and relationship marketing (Ahluwalia et al. 2000; Fournier 1998) might predict, ATL does not seem to moderate the reactions of participant consumers; they all display similar pro-challenger changes in their attitudes and behaviors, regardless of their ATL. That direct participation in the challenger's initiative overrides high ATL to produce universally favorable reactions can be explained by two factors. First, high perceived impact of the initiative provided participants with convincing and difficult-to-refute evidence of the challenger's concern for consumer welfare, making biased processing (e.g., counterarguments) of the information difficult (Ahluwalia 2000). Specifically, beliefs regarding initiative efficacy were pervasive among participants: respondents noted not only greater oral care behavior by their children (e.g., "I don't have to tell them so much to brush their teeth any more; and besides, they have learned how to floss really well"), but also their children's enhanced physical (i.e., dental health) and psychosocial (i.e., confidence, self-esteem) well-being (e.g., "I see that the program is doing an excellent job with them. My kids have more confidence, they feel good. It's good to see these 
changes"). In other words, the tangible benefits participant families obtained from the initiative seemed to convince them that it was not some superficial marketing ploy, but instead reflected the challenger's genuine care and concern for the community's welfare (e.g., "The company helps a lot; they want to help the lower income people." "They worry about us."”). Interestingly, participants also grasped the concomitant business motives (e.g., "It's a form of marketing not only to get their products out but also to help the community”), but were able to reconcile these with the genuine concern motives, commenting that it was a win-win situation (Ellen, Webb, and Mohr 2006).

Second, research on direct experience (e.g., Hoch and Deighton 1989) suggests that participation in the initiative is likely to trigger more elaborate internal rehearsal and central processing of information pertaining to the initiative, resulting in pro-challenger judgments that are perceived to be valid and credible and hence held with confidence despite the potentially biasing influence of consumers' existing loyalty to the leader. More formally, we hypothesize:

H1: The increase in consumers' ATC due to their participation in the challenger's CSR initiative will not vary with their ATL whereas the increase in consumers' ATC due to their mere awareness of the initiative will be greater among those with low ATL than those with high ATL.

H2: The increase in consumers' pro-challenger behaviors due to their participation in the challenger's CSR will not vary with their ATL whereas the increase in consumers' pro-challenger behaviors due to their mere awareness of the initiative will be greater among those with low ATL than those with high ATL.

The Driving Role of ATC in Participants' Pro-Challenger Behavior. A final theme that emerged from the focus groups pertains to the driving role of ATC in the participant consumers' pro-challenger behaviors. Specifically, participants spontaneously pointed to the role of ATC in their decision to purchase and support the challenger (i.e., "They are working on not the immediate but long term results...They give us the trust to continue using their products"). In other words, the initiative seemed to have transformed the participant - challenger relationship into a strong communal one wherein both parties care for each other and take on the other's problems as their own (Chua et al. 2008; Rousseau et al. 1999). As one 
participant consumer stated, "it helps you be more decisive when you see that a company does something for the community... why would I not buy it?" In line with their greater ATC and the communal nature of their relationship with the challenger, participant consumers went beyond just purchasing the brand to engage in a range of championing behaviors toward the challenger such as recommending the brand to others and volunteering for it. In contrast, such mutuality and consequent championing behaviors were less noticeable among aware consumers. Unlike participant consumers who pinpointed ATC to be the primary driving force behind their pro-challenger behaviors, aware consumers seemed to adopt a more calculative, transactional mindset, citing product quality (e.g., “...because it (the challenger) leaves a fresh breath," "it is recommended by dentists."), along with ATC, as inputs into their reactions to the challenger. These differences point to the qualitatively distinct drivers of the consumer-challenger relationship among the participant versus aware consumers. Specifically, research on relationship marketing suggests that while strong, long-term oriented relationships are driven by trust, weak, short-term oriented relationships are driven by transaction-specific satisfaction (e.g., product performance and price; Agustin and Singh 2005; Garbarino and Johnson 1999; Morgan and Hunt 1994). Moreover, trust fulfills the higher-order, social needs intrinsic in strong, relational exchanges whereas satisfaction fulfills only the lower-order, economic needs in transactional exchanges (Agustin and Singh 2005).

This driving role of ATC in participant (but not those merely aware) consumers' pro-challenger behaviors can also be understood in terms of attitudes based on direct experience (Fazio and Zanna 1981). ATC formed through participation in the challenger's initiative is likely to be more accessible, more persistent over time, and importantly, more likely to guide later behavior than ATC based on learning about the initiative through a second-hand, indirect source (i.e., mere awareness). In other words, it is the greater salience, or accessibility, of ATC among the participant consumers that determines, at least in part, its greater impact on their pro-challenger behaviors. In sum, we hypothesize,

H3: The increase in the strength of the link between ATC and pro-challenger behaviors due to participation will be greater than the increase due to mere awareness.

Next, we test our predictions through a field study involving the same CSR initiative. 


\section{Field Study}

\section{Method}

Design. Given that the challenger's initiative was already in place at the time of this study, we employed a quasi-experiment design: post-test only with a nonequivalent control group (Shadish, Cook, and Campbell 2002). More specifically, our field study has three groups: participant, (merely) aware, and unaware consumers. Participant consumers consisted of Hispanic parents whose children had either completed or were close to completing the oral health program. Non-participant consumers consisted of Hispanic parents from the same zip codes but whose children had not participated in the program (i.e., none of the children had ever participated) and were further divided into aware consumers and unaware consumers based on whether they were aware of the initiative prior to the survey. The unaware consumers served as a control group. We estimate the effects of participation in [awareness of] the challenger's initiative by comparing participant [aware] consumers to unaware consumers. Since the field setting of our experiment did not allow for randomization, it is possible that these three groups are not equivalent, an issue we attempt to address through analysis. We used a telephone survey administered by an independent marketing research company.

Respondents. We recruited participant consumers from six urban areas where the program was active using the same criteria used to recruit the focus group participants. The nonprofit organization (BGCA) was able to provide telephone contact information of 345 Hispanic families that satisfied our recruitment criteria. Care was taken to exclude all focus group participants. To motivate participation, those who completed the survey were automatically entered into two random drawings for $\$ 100$. However, even after several attempts to contact members of this sample, we were unable to reach a majority of the participant consumers. Reasons for this included invalid phone numbers, busy phone lines, calls that were unanswered or forwarded to the answering machine or voice mail, and respondents not being available to complete the survey. Our experience in accessing our sample is similar to that of prior research, which documents the various difficulties in surveying ethnic and minority groups, especially those with low literacy and low socio-economic status, such as the participant consumers in our study (Word 1997). We 
were ultimately able to reach 140 participant consumers, yielding 53 complete surveys. Given the low response rate $(15 \%)$, we compared the early respondents $(n=42)$ to the late ones (i.e., those who were reached after repeated contact attempts, $\mathrm{n}=11$ ) and found that they shared similar socio-demographic profiles as well as similar beliefs of and behaviors toward the challenger and the leader, allaying at least somewhat our concerns about non-response bias.

One thousand non-participant consumers were contacted from lists drawn from the marketing research company's database. We obtained 305 complete surveys (i.e., a 30.5\% response rate). Prior to the analyses, we deleted all observations with missing values on the key measures, resulting in a total sample size of 316, with 47 participant consumers and 269 non-participant consumers. In line with prior evidence of low CSR awareness (Alsop 2005; Du, Bhattacharya and Sen 2007; Sen et al. 2006), we find that only 36 of the 269 non-participant consumers were aware of the challenger's initiative, yielding 36 aware consumers and 233 unaware consumers. Table 1 provides the demographic characteristics of these three groups. While aware consumers are not meaningfully different from unaware consumers, participant consumers are more likely to be single, work full-time, and have lower levels of education and household income than unaware consumers, which to an extent explains the lower response rate among the participant consumers (i.e., they were at work and hence unavailable to respond to the survey call). To control for these differences, we included these demographic variables as covariates in all our analyses.

Insert table 1 about here

Measures. Two dummy variables were used to denote the three test groups: D1 $=1$ if the respondent is a participant consumer, else D1 $=0$; and D2 $=1$ if the respondent is an aware consumer, else D2 $=0$. $\mathrm{D} 1=0$ and D2 $=0$ denotes unaware consumers. Our other measures were developed based on prior research as well as our qualitative findings (see Appendix for details, including descriptive statistics). Pro-challenger behaviors were assessed through three distinct types of behavior: purchase of the challenger (Purchase $\left.{ }_{C}\right)$, likelihood to recommend the challenger $\left(\right.$ Recommend $\left._{C}\right)$, and resilience to negative publicity about the challenger ( Resilience $\left._{C}\right)$. These behaviors are in line with prior research on relationship marketing, which lists purchase (Agustin and Singh 2005; Garbarino and Johnson 1999; 
Morgan and Hunt 1994), recommending the brand (Reichheld 2003; Sirdeshmukh et al. 2002), and resilience to negative brand information (Ahluwalia et al. 2000; Bhattacharya and Sen 2003; Fournier 1998) as key indicators of consumer loyalty and championship behaviors.

ATC [ATL] was measured by two items that tap into consumer perceptions of the challenger's [leader's] genuine care and concern for their welfare (Agustin and Singh 2005; Chua et al. 2008; Johnson and Grayson 2005). In addition, we measured perceived quality of the challenger (PQC) and the leader (PQL) in terms of the perceived efficacy of each brand on three key product attributes that emerged from the focus groups: freshening breath, whitening teeth, and fighting cavities. The attribute of fighting cavities was measured using a reversed item and was dropped from our analysis due to its low correlation with the other two items. Finally, we collected measures pertaining to the challenger's initiative, including perceived impact of the initiative (for participant consumers only), and perceived intrinsic and extrinsic CSR motives (Ellen et al. 2006). Non-participant consumers were asked whether they were aware of the challenger's initiative before these questions; in case they were unaware, a brief description of the initiative was provided. Demographics were collected at the end. Table 2 contains the means of the key variables for the three groups. Table 3 contains the correlation matrix of the key variables.

Insert tables 2 and 3 about here

Our use of several single-item measures (e.g., Purchase ${ }_{C}$, Recommend $_{C}$, Resilience ${ }_{C}$ ) was guided by two considerations. First, as this study was only one part of a lengthy questionnaire, minimizing the possibility of respondent fatigue and/or impatience, particularly among our hard-to-reach vulnerable population, necessitated the use of single-item measures. At the same time, recent research comparing the predictive validity of multiple-item vs. single-item measures of the same constructs shows that when the object or attribute is concrete and unambiguous, single-item measures are equally effective and more efficient (Bergkvist and Rossiter 2007). Thus, on balance, single-item measures for familiar behaviors such as purchase and willingness to recommend seemed appropriate.

All measures were part of a longer phone survey administered in Spanish or English, depending on 
respondent preference. The survey was developed in English, translated to Spanish, and translated back to English to ensure the integrity of the measures. To minimize demand effects, we put the brand behavior questions first, then the questions on affective trust and perceived quality, and lastly those pertaining to the challenger's social initiative. Our research objectives were further concealed from the respondents by the fact that brand behaviors and beliefs were elicited for both the challenger and the leader.

We dummy coded the relevant demographic variables (marital status $=1$ if "married or living together," else marital status $=0$; employment status $=1$ if "work full-time or part-time," else employment status $=0$; income status $=1$ if total yearly household income is "over $\$ 30,000$," else income status $=0$; educational status $=1$ if have "some college education or higher," else education status $=0$ ). The dummy coding for these variables retained most of the information contained in the original nominal or ordinal scales (see Table 1) but made these variables amenable to inclusion as covariates in the regression analyses.

\section{Results}

Overview. We tested the hypotheses using a system of four regressions: (1) ATC predicted by participation (D1), awareness (D2), and ATL; (2) pro-challenger behaviors (i.e., Purchase , $_{\text {, }}$ Recommend $_{C}$, and Resilience ${ }_{C}$ ) predicted by participation (D1), awareness (D2), ATL, PQC, and ATC. Because of the recursive nature of this system and the possibility of correlated errors, we estimated the four equations simultaneously using seemingly unrelated regressions (SUR). Each model in this system included the relevant interactions of interest (H1 and H3), as well as the demographic variables as covariates. Additional regressions were run to provide direct evidence for $\mathrm{H} 2$. To enhance the interpretation of the regression coefficients in moderated regression models, we mean-centered all continuous independent variables (Aiken and West 1991).

$$
\begin{aligned}
& \text { ATC }= \beta_{0}+\beta_{1} \mathrm{D} 1+\beta_{2} \mathrm{D} 2+\beta_{3} \mathrm{ATL}+\beta_{4} \mathrm{D} 1 \times \mathrm{ATL}+\beta_{5} \mathrm{D} 2 \times \mathrm{ATL}+\beta_{6} \text { Martial Status }+\beta_{7} \\
& \text { Employment }+\beta_{8} \text { Income }+\beta_{9} \text { Education }+\varepsilon \\
& \text { Purchase }_{\mathrm{C}}= \beta_{0}+\beta_{1} \mathrm{D} 1+\beta_{2} \mathrm{D} 2+\beta_{3} \mathrm{ATL}+\beta_{4} \mathrm{PQC}+\beta_{5} \mathrm{ATC}+\beta_{6} \mathrm{D} 1 \times \mathrm{ATL}+\beta_{7} \mathrm{D} 2 \times \mathrm{ATL}+\beta_{8} \mathrm{D} 1 \times \\
& \mathrm{PQC}+\beta_{9} \mathrm{D} 2 \times \mathrm{PQC}+\beta_{10} \mathrm{D} 1 \times \mathrm{ATC}+\beta_{11} \mathrm{D} 2 \times \mathrm{ATC}+\beta_{12} \text { Martial Status }+\beta_{13}
\end{aligned}
$$




$$
\text { Employment }+\beta_{14} \text { Income }+\beta_{15} \text { Education }+\varepsilon
$$

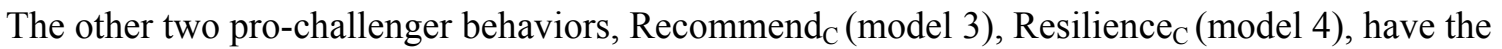

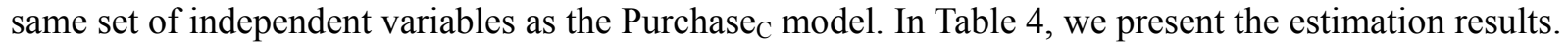

Effect of participation or awareness on ATC. Since participant consumers are described by D1 = 1 and $\mathrm{D} 2=0$, aware consumers by $\mathrm{D} 1=0$ and $\mathrm{D} 2=1$, and unaware consumers by $\mathrm{D} 1=0, \mathrm{D} 2=0$, the effect of participation (awareness) on ATC would be estimated in model 1 by $b_{1}+b_{4}$ ATL $\left(b_{2}+b_{5}\right.$ ATL). Specifically, $b_{1}\left(b_{2}\right)$ estimates the average effect of participation (awareness) on ATC, and $b_{4}\left(b_{5}\right)$ estimates whether the effect of participation (awareness) depends on the level of ATL. H1 predicts that the positive effect of participation on ATC will not vary with consumers' ATL, while the positive effect of awareness on ATC will be greater at lower levels of ATL. As expected, there is a main effect of participation on ATC $\left(\mathrm{b}_{1}=.58, \mathrm{t}=4.41, \mathrm{p}<.01\right)$, and a non-significant D1 x ATL interaction $\left(\mathrm{b}_{4}=-.13, \mathrm{t}=-.86, \mathrm{NS}\right)$, suggesting that the positive effect of participation on ATC does not vary across the levels of ATL.

On the other hand, we find a main effect of awareness on ATC $\left(\mathrm{b}_{2}=.40, \mathrm{t}=2.75, \mathrm{p}<.01\right)$ and a negative D2 x ATL interaction $\left(b_{5}=-.48, t=-2.93, p<.01\right)$, indicating that the effect of awareness on ATC gets larger as ATL decreases. To explicate the interaction, we examine the effect of awareness on ATC at several key levels of ATL (Aiken and West 1990) and find that the effect of awareness on ATC disappears when ATL is high (i.e., mean $+1 \mathrm{SD}=4.79$, effect of awareness on $\mathrm{ATC}=.00, \mathrm{t}=.01$, NS), becomes significant when ATL is at the mean (i.e., 3.96, effect of awareness $=.40, t=2.75, p<.01$ ), and gets even bigger when ATL is low (i.e., mean $-1 \mathrm{SD}=3.13$, effect of awareness on $\mathrm{ATC}=.81, \mathrm{t}=3.76, \mathrm{p}$ $<.01)$. Therefore, $\mathrm{H} 1$ is supported.

Insert table 4 about here

Effect of participation or awareness on pro-challenger behaviors. To test $\mathrm{H} 2$, we ran separate regression models analogous to model 1, where pro-challenger behaviors (Purchase ${ }_{C}$, Recommend $_{C}$, and Resilience $_{\mathrm{C}}$ ) were predicted by participation (D1), awareness (D2), ATL, and the two way interactions. H2 predicts that the positive effects of participation on pro-challenger behaviors will not vary with consumers' ATL. Consistent with H2, there are positive main effects of participation on Purchase ${ }_{\mathrm{C}}\left(\mathrm{b}_{1}\right.$ 
$=.53, \mathrm{t}=2.78, \mathrm{p}<.01), \operatorname{Recommend}_{\mathrm{C}}\left(\mathrm{b}_{1}=1.01, \mathrm{t}=5.11, \mathrm{p}<.01\right)$ and Resilience $\mathrm{C}_{\mathrm{C}}\left(\mathrm{b}_{1}=.57, \mathrm{t}=2.73, \mathrm{p}\right.$ $<.01$ ), and the D1 x ATL interaction is not significant in all three models (Purchase $\mathrm{C}_{\mathrm{C}} \mathrm{b}_{4}=-.06, \mathrm{t}=-.26$, $\mathrm{NS}$; Recommend $\mathrm{C}_{\mathrm{C}}: \mathrm{b}_{4}=-.07, \mathrm{t}=-.29$, NS; Resilience $\left.{ }_{C}: \mathrm{b}_{4}=-.23, \mathrm{t}=-.96, \mathrm{NS}\right)$.

$\mathrm{H} 2$ also predicts that the positive effects of awareness on pro-challenger behaviors will diminish with increasing levels of ATL. This is supported in the case of two pro-challenger behaviors, Recommend , Resilience $_{C}$, but not Purchase $e_{C}$. For Recommend ${ }_{C}$, there is a main positive effect of awareness $\left(b_{2}=.71, t\right.$ $=3.21, \mathrm{p}<.01)$ and a negative D2 $\times$ ATL interaction $\left(\mathrm{b}_{5}=-.58, \mathrm{t}=-2.32, \mathrm{p}<.05\right)$. For Resilience $\mathrm{C}_{\mathrm{C}}$, the main effect of awareness is significant at the .10 level $\left(\mathrm{b}_{2}=.38, \mathrm{t}=1.64, \mathrm{p}<.10\right)$, and there is a negative D2 x ATL interaction $\left(b_{5}=-.88, t=-3.36, p<.01\right)$. Analysis at key levels of ATL reveals that for both these variables, the effects of awareness disappear when ATL is high (i.e., mean $+1 \mathrm{SD}=4.79$, effect of awareness on Recommend $\mathrm{C}_{\mathrm{C}}=.23, \mathrm{t}=.82$, NS; effect of awareness on Resilience $\mathrm{C}_{\mathrm{C}}=-.35, \mathrm{t}=-1.18$, NS), become significant when ATL is at its mean level (i.e., 3.96; effect of awareness on $\operatorname{Recommend}_{\mathrm{C}}=.71, \mathrm{t}$ $=3.21, \mathrm{p}<.01$; effect of awareness on Resilience $\mathrm{C}_{\mathrm{C}}=.38, \mathrm{t}=1.64, \mathrm{p}<.10$ ), and get bigger when ATL is low (i.e., mean $-1 \mathrm{SD}=3.13$, effect of awareness on $\operatorname{Recommend}_{\mathrm{C}}=1.19, \mathrm{t}=3.71, \mathrm{p}<.01$; effect of awareness on Resilience $\left.\mathrm{C}_{\mathrm{C}}=1.11, \mathrm{t}=3.25, \mathrm{p}<.01\right)$. On the other hand, while there is a positive effect of awareness on Purchase ${ }_{\mathrm{C}}\left(\mathrm{b}_{2}=.44, \mathrm{t}=2.08, \mathrm{p}<.05\right)$, the expected negative D2 x ATL interaction is not significant $\left(b_{5}=-.15, t=-.64, N S\right)$. That is, the positive effect of awareness on Purchase $e_{C}$ does not vary with levels of ATL. In sum, H2 is supported in two out of three pro-challenger behaviors.

Effects of participation or awareness on the link between ATC and pro-challenger behaviors. Finally, $\mathrm{H} 3$ predicts that the increase in the strength of the link between ATC and pro-challenger behaviors due to participation will be greater than the increase due to mere awareness. The link between ATC and pro-challenger behaviors are estimated in models $2-4$ as follows: $b_{5}$ for unaware consumers, $b_{5}+b_{10}$ for participant consumers, and $b_{5}+b_{11}$ for aware consumers, with $b_{10}\left(b_{11}\right)$ estimating the change in the ATC - behavior link due to participation (awareness). A positive $b_{10}$ would indicate that participation strengthens the ATC - behavior link. Consistent with $\mathrm{H} 3$, we find that participation has strengthened the ATC - pro-challenger behavior link (Purchase ${ }_{C}: b_{10}=.53, t=1.79, p<.10$; Recommend ${ }_{C}: b_{10}=.63, t=$ 2.07, $\mathrm{p}<.05 ;$ Resilience $\left.\mathrm{b}_{\mathrm{C}} \mathrm{b}_{10}=.74, \mathrm{t}=2.22, \mathrm{p}<.05\right)$, but awareness has not (Purchase $\mathrm{b}_{\mathrm{C}}: \mathrm{b}_{11}=-.21, \mathrm{t}=$ 
$-.74, \mathrm{NS}$; Recommend $\mathrm{C}: \mathrm{b}_{11}=.25, \mathrm{t}=.85, \mathrm{NS}$; Resilience $\left.{ }_{\mathrm{C}}: \mathrm{b}_{11}=.43, \mathrm{t}=1.30, \mathrm{NS}\right)$. More specifically, we find that while ATC is not a significant predictor of the pro-challenger behaviors for unaware consumers $\left(\right.$ Purchase $_{C}: b_{5}=.04, t=.37, N S$; Recommend ${ }_{C}: b_{5}=.14, t=1.29$, NS; Resilience $: b_{5}=.11, t$ $=.87, \mathrm{NS}), \mathrm{ATC}$ is positive related to all three pro-challenger behaviors for participant consumers Purchase $_{\mathrm{C}}: \mathrm{b}_{5}+\mathrm{b}_{10}=.04+.53=.57, \mathrm{t}=2.07 ; \mathrm{p}<.05 ;$ Recommend $_{\mathrm{C}}: \mathrm{b}_{5}+\mathrm{b}_{10}=.14+.63=.77, \mathrm{t}=2.73$, $\mathrm{p}<.01 ;$ Resilience $\left.\mathrm{C}: \mathrm{b}_{5}+\mathrm{b}_{10}=.11+.74=.85, \mathrm{t}=2.73, \mathrm{p}<.01\right)$. Finally, ATC is not a significant predictor of the aware consumers' Purchase ${ }_{C}$ or $\operatorname{Recommend~}_{C}\left(\right.$ Purchase $_{C}: b_{5}+b_{11}=.04+(-.22)=-.18, t$ $=-.65 ; \mathrm{NS}$; Recommend $\left.{ }_{\mathrm{C}} \mathrm{b}_{5}+\mathrm{b}_{11}=.14+.25=.39, \mathrm{t}=1.44, \mathrm{NS}\right)$, but its effect on Resilience $\mathrm{C}$ approaches significance $\left(\mathrm{b}_{5}+\mathrm{b}_{11}=.11+.43=.54, \mathrm{t}=1.76, \mathrm{p}<.10\right)$. In sum, we find support for H3.

Additional Analysis. Given H3, we also examine the effects of program participation versus mere awareness on the strength of the link between PQC and the pro-challenger behaviors. These are estimated in models $2-4$ as follows: $b_{4}$ for unaware consumers, $b_{4}+b_{8}$ for participant consumers, and $b_{4}+b_{9}$ for aware consumers, with $\mathrm{b}_{8}\left(\mathrm{~b}_{9}\right)$ estimating the change in the PQC - behavior link due to participation (awareness). As can be seen from Table 4, $\mathrm{b}_{4}$ is positive in all three models (all p's $<.01$ ), indicating that PQC drives pro-challenger behaviors for unaware consumers. More interestingly, this PQC - behavior link is significantly weakened by participation but not by awareness, as indicated by a negative $b_{8}$ (Purchase $_{C}: b_{8}=-.51, t=-2.07, p<.05 ;$ Recommend $_{C}: b_{8}=-.67, t=-2.68, p<.01 ;$ Resilience $_{C}: b_{5}=-.62, t$ $=-2.25, \mathrm{p}<.05)$, and a nonsignificant $\mathrm{b}_{9}($ all $\mathrm{p}$ 's $>.10)$. More detailed analysis indicates that these three consumer groups have different drivers of pro-challenger behaviors: participant consumers' pro-challenger behaviors are driven by ATC (all p's $<.05$ ) but not by PQC (all p's $>.10$ ), unaware consumers' pro-challenger behaviors are driven not by ATC (all p's $>.10$ ) but by PQC (all p's $<.01$ ), and aware consumers' behavioral drivers lie somewhere in-between (e.g., aware consumers' Purchase ${ }_{\mathrm{C}}$ is driven by $\mathrm{PQC}$ but their Resilience $\mathrm{C}_{\mathrm{C}}$ is driven by ATC). Given that short-term, transactional consumer-brand relationships are primarily driven by transaction-specific assessments such as satisfaction with product quality, whereas long-term, communal relationships are driven by relational constructs such as trust (Agustin and Singh 2005; Garbarino and Johnson 1999), our results highlight the qualitatively distinct nature of the consumer-challenger relationship across these three consumer groups. More 
specifically, these results suggest that through this initiative the challenger has successfully built a communal, trust-based relationship with participant consumers.

\section{Validity Checks}

In addition to including socio-demographic variables as covariates in all our regression analyses, we conducted some additional analyses to strengthen the validity of our findings in the face of alternative explanations. First and foremost, it is possible that the group-wise differences in ATC and pro-challenger behaviors might be due not so much to initiative participation or awareness, but to some general differences across the three consumer groups. These could include group-wise differences in information processing (e.g., participant consumers may have lower need-for-cognition and be less skeptical of marketer actions) or decision-making criteria (e.g., participant consumers might weight quality less heavily in their purchase decisions) or a more general self-selection bias. While such confounds are always a concern in studies that are not purely experimental in nature, both our focus group (e.g., quotes like "They are working on not the immediate but long term results...They give us the trust to continue using their products." "This means they [challenger] care about our welfare...”) and survey data (e.g., the positive correlation between perceived impact of initiative and ATC, $\mathrm{r}=.36, \mathrm{p}<.01$ ) point to the causal role of initiative participation or awareness per se. As well, the moderating effects of ATL on the links between awareness and both ATC and pro-challenger behaviors allay somewhat the concern that aware consumers are fundamentally different from unaware consumers.

We also conducted some additional analyses to examine these alternative explanations. For instance, it is possible that consumers with more positive a priori beliefs about the challenger chose to participate in (or were more likely to be aware of) the CSR initiative, and that perhaps only those participant consumers with the most positive a priori beliefs about the challenger actually completed the survey (i.e., a self-selection bias). If this is the case, then it is reasonable to expect, in this essentially two-brand market, that these groups would also differ in their a priori beliefs and behaviors pertaining to the leader. However, with the exception of purchase ${ }_{\mathrm{L}}{ }^{4}$, these three groups share similar leader-related beliefs and behaviors (Table 2), diminishing somewhat our concern that our findings are due to a self-selection bias. In addition, 
among the participant consumers, early and late respondents appear to be no different in terms of demographic characteristics, as well as their beliefs and behaviors toward either the challenger or the leader. Therefore, eagerness to respond to the survey does not seem to be correlated with challenger-specific factors.

A more specific alternative account would suggest that the more favorable reactions of the participant versus the aware consumers are driven by the former's lower need for cognition and lower skepticism, both of which have been linked to lower socio-economic status (Cacioppo, Petty, Feinstein, and Jarvis, 1996). However, our focus group discussions suggest that the participant consumers have thought about the initiative and are fully cognizant of the profit-related motives behind the challenger's initiative (e.g., "it's a form of marketing not only to get their products out but also to help the community."). This is also reflected in the similarity across the three groups in the extent to which they make extrinsic attributions (F $<1$, NS; Table 2), suggesting that they share similar levels of skepticism, at least in terms of articulating the business motives underlying the challenger's initiative. On the other hand, participant consumers do make greater intrinsic attributions than the other two groups, which our analysis shows to be positively related to the perceived impact of the initiative $(\mathrm{r}=.46, \mathrm{p}<.01)$. This indicates that participant consumers did not automatically attribute intrinsic motives to the challenger, but based these, instead, on actual initiative-specific evidence. In other words, the correlations between the perceived impact of the initiative and intrinsic attributions, and that between perceived impact and ATC, indicate that participant consumers' attitudinal changes were not driven as much by peripheral cues (e.g., CSR program equals a good brand) as by the extent to which the program actually made a difference in their lives (i.e., a central cue).

It is also possible that our $\mathrm{H} 3$ results are caused not by program participation per se but because the participant group is intrinsically different from the aware and unaware groups in its weighting of relevant brand-specific criteria, such as affective trust, perceived quality. If this is the case, then such differences should also be apparent in their reactions to the leader brand. We examined this by regressing the three pro-leader behaviors (Purchase ${ }_{\mathrm{L}}$, Recommend $_{\mathrm{L}}$, and Resilience ${ }_{\mathrm{L}}$ ) on participation (D1), awareness (D2), PQL, ATL, and relevant two way interactions. As usual, demographic variables were included as 
covariates. In all three models, PQL is significant in predicting pro-leader behaviors (all p's $<.01$ ), while ATL and all two-way interactions are non-significant, indicating that, unlike in the case of pro-challenger behaviors, these three consumer groups' pro-leader behaviors are similarly determined. This finding allays substantially the concern that these three consumer groups are intrinsically different in terms of the criteria they use to evaluate oral care brands.

A more specific concern pertains to what exactly drives the effects of participation on pro-challenger behaviors. One could argue, for instance, that the positive effects of participation might be due to the greater product exposure accompanying participation rather than the benefits thus obtained. Several factors help rule out this possibility. First, if it is greater product experience that underlies the observed effects of participation, then the role of PQC, gleaned through such experience, in driving pro-challenger behaviors should be strongest among participant consumers. We find the opposite: the link between PQC [ATC] and pro-challenger behaviors is weakest [strongest] among participant consumers compared to the other two groups (Table 4). Second, the positive correlation between the perceived impact of the initiative and ATC supports the focus group finding that it is program participation, with its concurrent benefits (e.g., enhanced oral health and well-being among the participant children), rather than product experience per se, that has engendered greater ATC among the participant consumers, producing more favorable pro-challenger behaviors. At the same time, the aforementioned positive correlation between perceived impact of the initiative and ATC reduces the concern that the higher levels of ATC among participant consumers may be due to a self-perception dynamic (i.e., I chose to participate in the initiative, therefore I must really trust the challenger). Participant consumers' ATC, if caused by a self-perception process, should not correlate with the perceived impact of the initiative. Third, it is the children, not the parents who completed our survey, who physically participated in the initiative, where such product exposure would have occurred to a greater extent. Thus, the reactions of parents are not likely to be as influenced by product exposure per se.

Finally, we also checked for common-method bias, which can be a problem in a survey study such as ours where data on both independent and dependent variables are collected from the same respondents using similar types of response scales (i.e., Likert scales). We checked for this potential problem using 
Harman's single-factor test (Podsakoff, MacKenzie, Lee and Podsakoff, 2003), which suggests that a substantial amount of common-method variance is present if (a) a single unrotated factor solution emerges from an exploratory factor analysis or (b) one general factor accounts for the majority of the covariance among the measures. With our data, the unrotated factor solution revealed five factors with Eigen values greater than one, accounting for $72.2 \%$ of the total variance, with the first unrotated factor accounting for $23.4 \%$ of the total variance. The absence of a general factor in the unrotated structure indicates that common-method bias does not pose a significant problem for our field study.

\section{General Discussion}

This research builds on the complementary CSR literatures in strategy and marketing to provide insight into the efficacy of CSR as a challenger's competitive weapon against a market leader. Based on focus groups and a quantitative field survey about a real-world CSR program, we find that the challenger can reap superior business returns among consumers who have participated in its CSR initiative, relative

to those who are merely aware. Specifically, participant consumers demonstrate the desired attitudinal and behavioral changes in favor of the challenger, regardless of their prior relationship to the leader, whereas aware consumers' reactions become increasingly less favorable as their relationship bond to the leader increases. As (if not more) importantly, participation, unlike mere awareness, transforms the consumer-challenger relationship from a transactional nature to a communal, trust-based one. Our findings provide the first micro-level empirical affirmation of the notion of strategic CSR (Kotler and Lee 2004; Porter and Kramer 2006): the superior business returns of a CSR initiative when it addresses a key concern of the brand's consumers and necessitates their active participation rather than having them be passive beholders. Our findings also highlight the need to take into account consumers' existing loyalty to a competitor when designing and implementing a CSR initiative and assessing its business returns.

\section{Theoretical Implications}

Our findings have implications for theories of CSR, persuasion, and competitive strategy. By 
examining consumer reactions to a real-world CSR initiative by a challenger brand in its attempt to make inroads into the incumbent's turf, we bring a micro-level psychological perspective to a macro-level strategic issue (e.g., Porter and Kramer 2006) - CSR's potential as a competitive lever - and paint a more nuanced, realistic picture of the business returns to CSR than prior research in marketing, which has focused overwhelmingly on single brand contexts. Most importantly, reflecting the scenarios where consumer participation is integral to the social program such as the aforementioned Dove Initiative, we differentiate between participant consumers and those who are merely aware, and document for the first time the qualitatively different reactions between the two groups. While aware consumers are likely to engage in biased processing of a CSR initiative to defend the brand they are loyal to, participant consumers who have a positive experience with the program are likely to be won over by the CSR initiative and enter into communal, trust-based relationship with the brand behind the social initiative. Our finding that direct participation in a brand's initiative can overcome consumers' strong bond with a competitor to produce desired attitudinal and behavioral change is interesting in light of the persuasion resistance literature (Ahluwalia 2000). We show that first-hand, positive experience with a brand's CSR initiative powerfully conveys the trustworthiness of the brand, despite consumers' motivation, if any, to discount or resist this information.

Further, our research attests to the pivotal yet thus far unexamined role of affective brand trust at the individual consumer level in driving the strategic returns to CSR, and examines the conditions under which it might matter the most. Specifically, the superior business returns among the participant consumers stem from their positive participative experience with the brand's CSR initiative, which not only engenders affective trust in that brand but also transform their relationship to it to one rooted in such trust. At the same time, we show that the reactions of merely aware consumers can range in favorability depending on their affective trust in the rival brand. In other words, affective trust in the market leader brand represents the competitive barrier a challenger must overcome to win consumers over from its rival, and therefore should be taken into consideration in the formulation of the latter's competitive strategy, CSR-based or otherwise.

In fact, a much debated question in competitive strategy pertains to how a challenger might take on a 
market leader, winning over the latter's loyal consumers (e.g., Morgan 2009; Shankar, Carpenter, and Krishnamurthi 1998). In light of extant thinking that when competing against a leader a challenger's superior marketing mix is often insufficient to surpass the incumbent brand's advantage (Bowman and Gatignon 1996; Shankar et al. 1998), our research shows, for the first time, the challenger's ability to leverage its CSR to overcome this incumbent advantage. Although our research does not allow a direct comparison between a CSR-based competitive strategy and a marketing mix-based one, it does suggest that the former, by driving home to consumers in tangible ways that "we have your best interests at heart," is uniquely effective at forging an affective bond. Such "straight to the heart" strategies are likely to be particularly effective in categories where product differentiation is minimal, evaluation of product performance is inherently ambiguous (i.e., credence products), or consumer involvement is low, rendering rational marketing mix-based arguments (e.g., a superior attribute) largely ineffective.

\section{Managerial Implications}

CSR can be implemented in various ways, such as donating a part of revenue to a cause, raising awareness of a social issue, or encouraging employees to volunteer in the local community. The superior business returns among the participant consumers relative to the aware consumers in our study highlight the importance of having a strategic CSR initiative that engages consumers, rather than treating CSR as an add-on, spectator sport. Our research suggests that when devising a CSR strategy, companies should focus on the important concerns of their target consumers, and try to actively involve their consumers in the resulting CSR initiatives. If a high percentage of a company's target consumers participate in its CSR efforts, the company will be able to reap maximal returns to such efforts. This is also consistent with recent thinking in the strategy literature (Davis 2005; Pettigrew 2009) that key consumer/societal problems (e.g., obesity, health, poverty, and environment) present unprecedented opportunities for companies to gain long term competitive advantage by creating both social and business value.

In contrast to such a strategic approach to CSR, many firms still treat CSR as cosmetic, public relation stunts, with some spending more on CSR advertising than on the initiatives themselves (Porter and Kramer 2002, 2006; Yoon, Gurhan-Canli, and Schwartz 2006). The drawbacks of such approaches are 
increasingly evident: they produce minimal social impact, generate consumer skepticism, and, consequently fail to deliver business value. As a contrast, our research suggests that in certain contexts CSR budgets may be better spent gaining the active participation of consumers rather than merely making them aware of these initiatives. Unlike program participation, which is likely to produce long-term, vivid beliefs about a brand's genuine desire and ability to improve the welfare of the participating consumers, the impact of CSR advertising, particularly when it is not a precursor to participation, is likely, in terms of actual pro-brand behaviors, to be more muted. At a minimum, then, a firm needs to weigh the pros of raising widespread awareness of its CSR efforts through advertising with the cons of its ultimately low potential to be of significant strategic worth (see also Sen et al. 2006). The ultimate design and implementation of CSR initiatives will depend, of course, on both the strategic benefits examined in this paper and the costs of achieving these benefits compared to other mechanisms for doing so.

Managers should note that a participative campaign per se does not guarantee success. The "perceived efficacy" of the initiative (i.e., the initiative's ability to make a difference in the participant consumers' lives) plays a big role in convincing consumers that the company has the community's best interests at heart. In turn, this leads to affective trust towards the brand and helps reshape loyalties. Thus, managers need to realize that a prerequisite to creating business value through CSR is the creation of social value. Interestingly, as our study results revealed (recall the focus group quotes) consumers are tolerant of market motives on the part of the company as long as the company is serious about making a difference in the social arena. In fact, many consumers even laud the fact that the sponsoring company has business interests as well behind its CSR initiative, as that ensures that they would put their market muscle behind their CSR. This implies that managers don't need to hide market motives and oversell their altruism while communicating CSR; this may even backfire if the target segment perceives things to be different on the ground.

Overall, for challengers aiming to make inroads against a market leader, our research showcases the efficacy of a CSR initiative as a competitive lever. Rather than competing head-to-head against the leader by making incremental improvements in product attributes or relying on price promotions, which the prior research has shown to be largely ineffective, the challenger brand can resort to an innovative CSR 
initiative, appealing to consumers' heart and reshaping the game of competition. Marketing research that reveals the levels of ATC and ATL in the target market would help managers make more informed decisions of the costs and benefits of a participative campaign versus one that raises awareness regarding the firm's CSR initiatives. Needless to say however, given that consumers with low ATL may switch over to the challenger based on knowledge of its CSR initiative, raising awareness among target consumer also has its benefits.

\section{Public Policy Implications}

Due to the potential comparative advantage of business over governments or non-profits (e.g., business competencies and resources) in solving certain social problems (Hess, Rogovsky, and Dunfee 2002; Porter and Kramer 2002), governments must encourage firms to play an active role in solving social issues that intersect with, rather than are peripheral to, their particular businesses: areas where the private sector can leverage their core competence and where the potential for joint social and business value creation is the greatest. For example, The White House task force on childhood obesity Report to the President (2010) emphasizes the importance of cross-sector partnership and role of private businesses. By describing an actual example of a partnership between a company and a nonprofit that was supported by the government, our study also sheds light on the critical complementary roles firms can play to governments and NGOs when they exercise their core competencies in responding to a social need (Mahoney, McGahan, and Pitelis 2009).

Note that social issues typically go through a life cycle from obscurity, indifference/inattention, salience only among opinion leaders, to center of attention in the media and legislative concerns, and finally to resolution (Waddock 2008 p.64). When appropriate, government should provide guidance or alert businesses about the importance or severity of certain nascent or emerging social issues, and call for actions from the private sector before they become prominent. The wake-up call to combat the epidemic of oral diseases by the 2000 Surgeon General report on oral health and the subsequent launch of the CSR initiative studied in this paper is a fine example of government providing such timely guidance. 


\section{Limitations and Future Research}

Due primarily to the real-world nature of this research, it has some methodological limitations. First, it was not possible to conduct a true experiment, wherein the outcomes could have been unequivocally attributed to initiative awareness or participation. Therefore, despite our validity checks, only controlled experiments can unequivocally rule out the alternative explanations for our results. Second, because of the real-world constraints in reaching a difficult-to-reach consumer segment (e.g., Word 1997), we only have a small sample of participant consumers in our field study. Similarly, due to the generally low awareness of the initiative (i.e., only $13.4 \%$ of non-participant consumers were aware), we only have a small sample of aware consumers. Third, while focusing only on Hispanic consumers increases the internal validity of our findings, future research should examine whether our results generalize to other groups, ethnic and otherwise. In addition, since we only examine the scenario of a challenger competing against a market leader, future research should broaden the competitive context to include a larger number of players as well as players with different market positions such as a niche player (e.g., Zhu, Singh, and Manuszak 2009). Finally, despite assurances from prior research (e.g., Bergkvist and Rossiter 2007), some of the more nuanced constructs, such as Resilience $_{\mathrm{C}}$ and CSR attributions, would probably have been better measured using multiple items.

More generally, our work opens up several important avenues for future research. First, future research might dig deeper into the aspects of participation that help build ATC. Although we show that participation in a brand's initiative builds ATC to overcome consumers' extant bond with a competitor and yield superior business returns, our research does not pinpoint exactly what it is about direct participation that drives ATC. While our qualitative study suggests that it is because participation presents convincing, hard-to-refute evidence of the challenger's trustworthiness, future research should examine the phenomenon in greater detail in a more controlled setting. Relatedly, it is expected that the valence of the participation experience, as well as the degree of ambiguity regarding the outcomes of participation, might affect the reactions of participant consumers. In our empirical context, both focus group discussions and the survey results indicate that the experience of participation is overwhelmingly positive and the outcomes are noticeable and relatively unambiguous (e.g., mean value of perceived impact of the 
initiative is 4.45 on a 5-point scale). Future research might investigate how these factors, valence of experience and the quality and ambiguity of program outcomes, impact participant consumers' reactions to the CSR initiative.

Additionally, given that providing direct experience is expensive, future research might examine factors that decrease consumers' resistance to CSR communication/advertising and help win them over, particularly when they have a strong bond to a competitor. For example, our study did not examine the media through which nonparticipant consumers became aware of the challenger's initiative, or the frequency and the content of the CSR communication (e.g., information on number of people benefited and amount of resources contributed) they were exposed to. Studies of persuasion have found that, relative to argument-based advertising, narrative- or drama-based advertising reduces counterargument, is processed empathically (Deighton, Romer and McQueen 1989), and is, furthermore, more effective at building consumer-brand connections (Escalas 2004). Accordingly, future research might examine how forms or tactics (argument-based or drama-based) of CSR advertising influence its effectiveness in light of consumers' motivation to resist attitude change.

Another interesting question for future investigation is the possible existence of a first-mover advantage for a brand that pioneers the use of CSR as a strategic lever in its market area. Our research attests to the power of CSR in reshaping a challenger's competition against a leader. However, what if the leader strikes back through its own CSR initiative? Will the timing and the proactivity of CSR strategy affect consumer reactions? Perhaps the late mover's initiative triggers more self-serving attributions (e.g., due to competitive pressure) and less intrinsic attributions, thus hindering its ability to build affective trust and drive pro-company behaviors. Finally, in addition to micro-level consumer reactions (e.g., affective trust and pro-brand behavior), future research could also examine the impact of a brand's CSR initiative, particularly participation therein, on its market share or customer lifetime value (i.e., the long-term effectiveness of its CSR strategy). 


\section{References}

Agustin, Clara, and Jagdip Singh (2005), “Curvilinear Effects of Consumer Loyalty Determinants in Relational Exchanges," Journal of Marketing Research, 42(1), 96-108.

Ahluwalia, Rohini (2000), "Examination of Psychological Processes Underlying Resistance to Persuation," Journal of Consumer Research, 27(2), 217-232.

Ahluwalia, Rohini, Robert E. Burnkrant, and H. Rao Unnava (2000), “Consumer Response to Negative Publicity: The Moderating Role of Commitment," Journal of Marketing Research, 37(2), 203-214.

Aiken, Leona S. and Stephen G. West (1991), Multiple Regression: Testing and Interpreting Interactions, Thousand Oaks, CA: Sage.

Alsop, R. J. (2005). Communicating Corporate Citizenship. Leading Perspectives by Business for Social Responsibility, Summer, 4-5.

Bergkvist, Lars, and John R. Rossiter (2007), “The Predictive Validity of Multiple-Item Versus

Single-Item Measures of the Same Constructs," Journal of Marketing Research, 44(2), 175-184.

Bhattacharya, C. B., and Sankar Sen (2003), "Consumer-Company Identification: A Framework for Understanding Consumers' Relationships with Companies," Journal of Marketing, 67 (April), 76-88.

Bowman, Douglas, and Hubert Gatignon (1996), "Order of Entry as a Moderator of the Effect of the Marketing Mix on Market Share,” Marketing Science, 15(3), 222-242.

Cacioppo, John T., Richard E. Petty, Jeffrey A. Feinstein, and W. Blair G. Jarvis (1996), "Dispositional Differences in Cognitive Motivation: The Life and Times of Individuals Varying in Need for Cognition,” Psychological Bulletin, Vol. 119, 197-253

Center for Disease Control and Prevention (2009), "Children's Oral Health," (Accessed July 18, 2009), http://www.cdc.gov/OralHealth/publications/factsheets/sgr2000_fs3.htm.

Chua, Roy Yong Joo, Paul Ingram, and Michael W. Morris (2008), "From the Head and the Heart: Locating Cognition- and Affect-Based Trust in Managers' Professional Networks," Academy of Management Journal, 51(3), 436-452. 
Cone, Carol, and Kristian Darigan (2010), "Cause Branding Picks up on a New Issue for Women and Girls," available at http://www.contributemedia.com/opinions_details.php?id=182, accessed August $16,2010$.

Cottrell, Catherine A., Steven L. Neuberg, and Norman P. Li (2007), "What Do People Desire in Others? A Sociofunctional Perspective on The Importance of Different Valued Characteristics," Journal of Personality and Social Psychology, 92(2), 208-231.

Davis, Ian (2005), "What is the Business of Business," McKinsey Quarterly, 3, 104-113.

Deighton, John, Daniel Romer, and Josh McQueen (1989), “Using Drama to Persuade,” Journal of Consumer Research, 16(3), 335-343.

Doney, Patricia M., and Joseph P. Cannon (1997), “An Examination of the Nature of Trust in Buyer-Seller Relationships,” Journal of Marketing, 61(2), 35-61.

Du, Shuili, C.B. Bhattacharya, and Sankar Sen (2007), "Reaping Relational Rewards from Corporate Social Responsibility: The Role of Competitive Positioning," International Journal of Research in Marketing, 24(3), 224-41.

--, Sankar Sen, and C.B. Bhattacharya (2008), "Exploring the Social and Business Returns of a Corporate Oral Health Initiative Aimed at Disadvantaged Hispanic Families," Journal of Consumer Research, $35(3), 483-494$.

Eagly, Alice H., and Shelly Chaiken (1995), “Attitude Strength, Attitude Structure, and Resistance to Change," in Attitude Strength: Antecedents and Consequences, Vol. 4, ed. Richard E. Petty and Jon A. Krosnick, Mahwah, NJ: Erlbaum, 413-432.

Eisenhardt, Kathleen M. (1989), "Building Theory from Case Study Research,” Academy of Management Review, 14, 532-550.

Ellen, Pam Scholder, Deborah J. Webb, and Lois A. Mohr (2006), "Building Corporate Associations: Consumer Attributions for Corporate Socially Responsible Programs," Journal of the Academy of Marketing Science, 34 (2), 147-157.

Escalas Jennifer Edson (2004), "Narrative Processing: Building Consumer Connections to Brands," Journal of Consumer Psychology, 14(1/2), 168-180. 
Fazio, Russell H., and Mark P. Zanna (1981), "Direct Experience and Attitude-Behavior Consistency,” in Advances in Experimental Social Psychology, Ed. L. Berkowitz, Vol. 14, 161-202.

Fisher-Owen, Susan A., Judith C. Barker, Sally Adams, Lisa H. Chung, Stuart A. Gansky, Susan Hyde, and Jane A. Weintraub (2008), “Giving Policy Some Teeth: Routes to Reducing Disparities in Oral Health," Health Affairs, 27(2), 404-412.

Fournier, Susan (1998), "Consumers and Their Brands: Developing Relationship Theory in Consumer Research," Journal of Consumer Research, 24(4), 343-373.

Garbarino, Ellen, and Mark S. Johnson (1999), “The Different Roles of Satisfaction, Trust, and Commitment in Customer Relationships," Journal of Marketing, 63(2), 70-87.

General Mills (2010), “Champions for Healthy Kids,” Available at http://www.generalmills.com/en/Responsibility/Community Engagement/Grants/Champions for he althy kids.aspx, Accessed August 3, 2010,

Girl Scouts (2010), “Uniquely ME! The Girl Scout/Dove Self-Esteem Program,” Available at http://www.girlscouts.org/program/program_opportunities/leadership/uniquelyme.asp, Accessed August 3, 2010.

Godfrey, Paul C., Craig B. Merrill and Jared M. Hansen (2009), "The Relationship between Corporate Social Responsibility and Shareholder Value: An Empirical Test of the Risk Management Hypothesis," Strategic Management Journal, 30, 425-445.

Hess, David, Nikolai Rogovsky, and Thomas W. Dunfee (2002), “The Next Wave of Corporate Community Involvement: Corporate Social Initiatives," California Management Review, 44(2), $110-125$.

Hoch, Stephen J., and John Deighton (1989), "Managing What Consumer Learn from Experience,” Journal of Marketing, 53(2), 1-20.

Holmes, John G., and John K. Rempel (1989), “Trust in Close Relationships,” in Review of Personality and Social Psychology, Ed. C. Hendrick, Vol. 10, 187-220, London: Sage.

Johnson, Devon, and Kent Grayson (2005), "Cognitive and Affective Trust in Service Relationships," Journal of Business Research, 58, 500-507. 
Kotler, Philip, and Nancy Lee (2004), "Best of Breed," Stanford Social Innovation Review, 14-23.

--, and -- (2005), Corporate Social Responsibility: Doing the Most Good for Your Company and Your Cause, John Wiley \& Sons, Inc.: Hoboken, NJ.

Lackman, Conway and John M. Lanassa (1993), "Family Decision-Making Theory: An Overview and Assessment," Psychology and Marketing, 10 (2), 81-93.

Lemon, Katherin N., John Roberts, Russell S. Winer, and Priya Raghubir (2010), "Why, When, and How Should the Effect of Marketing Be Measured? A Stakeholder Perspective for Corporate Social Responsibility Metrics," Journal of Public Policy and Marketing, 29(1).

Lewit, Eugene M. and Nancy Kerrebrock (1998), “Child Indicators: Dental Health,” The Future of Children, 8(1), 133-42.

MaHoney, Joseph T., Anita M McGahan, and Christos N. Pitelis (2009), “The Interdependence of Private and Public Interests," Organization Science, 20(6), 1034-1052.

Margolis, Joshua D., and James P. Walsh, “Misery Loves Companies: Rethinking Social Initiatives by Business," Administrative Science Quarterly, 48(2), 268-305.

McAllister, Daniel J. (1995), “Affect- and Cognition-Based Trust as Foundations for Interpersonal Cooperation in Organizations," Academy of Management Journal, 38, 24-59.

McKinsey Quarterly (2009), "McKinsey Global Survey Results: Valuing Corporate Social Responsibility," February.

Morgan, Adam (2009), Eating the Big Fish: How Challenger Brands Can Compete Against Brand Leaders, Hoboken, NJ: Wiley \& Sons.

Morgan, Robert M., and Shelby D. Hunt (1994), “The Commitment-Trust Theory of Relationship Marketing," Journal of Marketing, 58(3), 20-39.

Rempel, John K., John G. Holmes, and Mark P. Zanna (1985), “Trust in Close Relationships,” Journal of Personality and Social Psychology, 49(1), 95-112.

Pettigrew, Andrew W. (2009), "Corporate Responsibility in Strategy," in Mainstreaming Corporate Responsibility, Eds. N. Craig Smith, and Gilbert Lenssen, 12-20, West Sussex, England: Wiley \& Sons Ltd. 
Podsakoff, Philip M., Scott B. Mackenzie, Jeong-Yeon Lee, and Nathan P. Podsakoff (2003), "Common Method Bias in Behavioral Research: A Critical Review of the Literature and Recommended Remedies,” Journal of Applied Psychology, 88(5), 879-904.

Porter, Michael E. and Mark R. Kramer (2002), “The Competitive Advantage of Corporate Philanthropy," Harvard Business Review, 80(12), 56-69.

--, and -- (2006), “Strategy \& Society: The Link between Competitive Advantage and Corporate Social Responsibility," Harvard Business Review, 84 (12), 78-92.

Reichheld, Frederick F. (2003), “The One Number You Need to Grow,” Harvard Business Review, 81(12), 46-54.

Rousseau, Denise, Sim Sitkin, Ronald Brut, and Colin Camerer (1999), "Not So Different after All: A Cross-Discipline View of Trust," Academy of Management Review, 23(3), 393-404.

Sen, Sankar, C.B. Bhattacharya, and Daniel Korschun (2006), “The Role of Corporate Social Responsibility in Strengthening Multiple Stakeholder Relationships: A Field Experiment," Journal of the Academy of Marketing Science, 34(2), 158-166.

Shadish, William R., Thomas D. Cook, and Donald T. Campbell (2002), Experimental and Quasi-Experimental Designs for Generalized Causal Inference, Boston MA: Houghton Mifflin. Shankar, Venaktesh, Gregory S. Carpenter, and Lakshman Krishnamurthi (1998), "Late Mover Advantage: How Innovative Late Entrants Outsell Pioneers," Journal of Marketing Research, 35(1), 54-70. Simmons, Carolyn J., and Karen L. Becker-Olsen (2006), “Achieving Marketing Objectives through Social Sponsorships," Journal of Marketing, 70(4), 154-169.

Sirdeshmukh, Deepak, Jagdip Singh, and Barry Sabol (2002), “Consumer Trust, Value, and Loyalty in Relational Exchanges," Journal of Marketing, 66 (January), 15-37.

Smith, N. Craig (2003), “Corporate Social Responsibility: Whether or How?” California Management Review, 45(4), 52-76.

Unilever (2010), “Dove,” Available at http://www.unilever.com/brands/personalcarebrands/dove/index.aspx, Accessed August 3, 2010 U.S. Department of Health and Human Services (2000), "Oral Health in America: A Report of the 
Surgeon General—Executive Summary," Rockvile, MD: U.S. Department of Health and Human Services, National Institute of Dental and Craniofacial Research.

Waddock, Sandra (2008), Leading Corporate Citizens: Vision, Values, and Value Added, $3^{\text {rd }}$ Ed, McGraw-Hill/Irwin, New York, NY, 10020.

White House Task Force on Childhood Obesity Report to the President (2010), Available at http://www.letsmove.gov/pdf/TaskForce_on_Childhood_Obesity_May2010_FullReport.pdf

Word, David L. (1997), “Who Responds/Who Doesn’t? Analyzing Variation in Mail Response Rates During the 1990 Census," Population Division Working Paper No.19, Washington, DC: U.S. Bureau of the Census.

Yoon, Yeosun, Zeynep Gurhan-Canli, and Norbert Schwarz (2006), “The Effect of Corporate Social Responsibility (CSR) Activities on Companies with Bad Reputations," Journal of Consumer Psychology, 16(4), 377-390.

Zhu, Ting, Vishal Singh, and Mark D. Manuszak (2009), "Market Structure and Competition in the Retail Discount Industry,” Journal of Marketing Research, Vol. 46 (4), 453-466. 


\section{Footnotes}

${ }^{1} \mathrm{CSR}$ actions can be at the company level, brand level, or both, in this paper we use company and brand interchangeably to capture the range of company-brand relationships (i.e., from corporate brands to standalone brands/individual brands).

${ }^{2}$ Here we describe the social initiative as it was at the time when this research was conducted. The initiative has evolved since then.

${ }^{3}$ Of oral care products, we chose to focus only on toothpaste because the focus group discussions revealed that, interestingly, consumers are brand-conscious with regard to toothpaste but not to toothbrushes. When purchasing toothbrushes, respondents said they often use criteria other than brand, such as the size, shape or texture of bristle, and whether the toothbrush is on sale.

${ }^{4}$ Participant consumers are less likely to purchase the leader than unaware consumers $(\mathrm{p}<.05)$, probably due to the fact that the former buy the challenger more frequently. 
TABLE 1

SAMPLE CHARACTERISITCS

\begin{tabular}{|c|c|c|c|}
\hline & $\begin{array}{c}\text { Participant } \\
\text { Consumers } \\
\quad(n=47)\end{array}$ & $\begin{array}{c}\text { Aware } \\
\text { Consumers } \\
(\mathrm{n}=36)\end{array}$ & $\begin{array}{c}\text { Unaware } \\
\text { Consumers } \\
(n=233)\end{array}$ \\
\hline \multicolumn{4}{|l|}{ Marital status } \\
\hline Single & $23.4 \%$ & $5.6 \%$ & $9.9 \%$ \\
\hline Married/Living together & $63.8 \%$ & $72.2 \%$ & $77.7 \%$ \\
\hline Widowed, divorced, or separated & $12.8 \%$ & $22.2 \%$ & $12.4 \%$ \\
\hline \multicolumn{4}{|l|}{ Employment status } \\
\hline Work full-time & $55.3 \%$ & $41.7 \%$ & $40.8 \%$ \\
\hline Work part-time & $6.4 \%$ & $11.1 \%$ & $17.2 \%$ \\
\hline Unemployed or student & $38.3 \%$ & $47.1 \%$ & $42.0 \%$ \\
\hline \multicolumn{4}{|l|}{ Education } \\
\hline Some or finished grade school & $19.6 \%$ & $33.4 \%$ & $22.0 \%$ \\
\hline Some or finished high school & $71.8 \%$ & $36.1 \%$ & $48.5 \%$ \\
\hline Some college or higher & $8.6 \%$ & $30.5 \%$ & $29.5 \%$ \\
\hline \multicolumn{4}{|l|}{ Household income } \\
\hline Under $\$ 30,000$ & $76.6 \%$ & $55.5 \%$ & $58.4 \%$ \\
\hline$\$ 30,000-\$ 49,999$ & $19.2 \%$ & $22.3 \%$ & $23.6 \%$ \\
\hline$\$ 50,000$ and over & $4.2 \%$ & $22.2 \%$ & $18.0 \%$ \\
\hline
\end{tabular}


TABLE 2

MEANS AND STANDARD DEVIATIONS OF KEY VARIABLES BY GROUPS

\begin{tabular}{|c|c|c|c|}
\hline & $\begin{array}{l}\text { Participant Consumers } \\
\qquad(\mathrm{n}=47)\end{array}$ & $\begin{array}{c}\text { Aware Consumers } \\
\qquad(\mathrm{n}=36)\end{array}$ & $\begin{array}{c}\text { Unaware Consumers } \\
(\mathrm{n}=233)\end{array}$ \\
\hline Perceived Impact of & 4.45 & -- & -- \\
\hline Initiative & $(.58)$ & & \\
\hline \multirow[t]{2}{*}{ Intrinsic Attributions } & 4.49 & 4.06 & 3.95 \\
\hline & $(.55)$ & $(.75)$ & $(.86)$ \\
\hline \multirow[t]{2}{*}{ Extrinsic Attributions } & 3.23 & 3.53 & 3.32 \\
\hline & $(1.31)$ & $(1.11)$ & $(1.06)$ \\
\hline \multirow[t]{2}{*}{ ATC } & 4.26 & 4.00 & 3.64 \\
\hline & $(.64)$ & $(.88)$ & $(.85)$ \\
\hline \multirow[t]{2}{*}{ PQC } & 4.03 & 4.18 & 3.76 \\
\hline & $(.83)$ & $(.67)$ & $(.80)$ \\
\hline \multirow[t]{2}{*}{ Purchase $_{C}$} & 3.21 & 3.11 & 2.70 \\
\hline & $(1.16)$ & $(.98)$ & $(1.20)$ \\
\hline \multirow[t]{2}{*}{ Recommend $_{C}$} & 3.68 & 3.28 & 2.64 \\
\hline & $(.91)$ & $(.97)$ & $(1.30)$ \\
\hline \multirow[t]{2}{*}{ Resilience $_{C}$} & 3.11 & 2.81 & 2.55 \\
\hline & $(1.27)$ & $(1.43)$ & $(1.28)$ \\
\hline \multirow[t]{2}{*}{ ATL } & 4.00 & 4.11 & 3.93 \\
\hline & $(.85)$ & $(.90)$ & $(.82)$ \\
\hline \multirow[t]{2}{*}{ PQL } & 4.02 & 4.23 & 4.10 \\
\hline & $(.83)$ & $(.97)$ & $(.77)$ \\
\hline \multirow[t]{2}{*}{ Purchase $_{\mathrm{L}}$} & 3.51 & 3.78 & 3.89 \\
\hline & $(1.12)$ & $(1.12)$ & $(1.18)$ \\
\hline \multirow[t]{2}{*}{ Recommend $_{L}$} & 3.53 & 3.47 & 3.32 \\
\hline & $(.78)$ & $(.99)$ & $(1.23)$ \\
\hline \multirow[t]{2}{*}{ Resilience $_{\mathrm{L}}$} & 2.81 & 2.86 & 2.93 \\
\hline & $(1.21)$ & $(1.36)$ & $(1.23)$ \\
\hline
\end{tabular}


TABLE 3

DESCRIPTIVE STATISTICS AND CORELATION MATRIX

\begin{tabular}{lcccccccccc}
\hline & $\mathrm{n}$ & Mean & S.D & $1^{\mathrm{a}}$ & 2 & 3 & 4 & 5 & 6 & 7 \\
1. Perceived Impact of & 47 & 4.45 & .48 & & & & & & & \\
Initiative & & & & & & & & & \\
2. Intrinsic Attributions & 316 & 4.04 & .83 & $.46^{* *}$ & & & & & \\
3. Extrinsic Attributions & 316 & 3.33 & 1.10 & -.21 & -.01 & & & & \\
4. ATC & 316 & 3.77 & .86 & $.36^{* *}$ & $.46^{* *}$ & -.06 & & & & \\
5.PQC & 316 & 3.85 & .80 & $.26^{+}$ & $.32^{* *}$ & -.02 & $.58^{* *}$ & & & \\
6. Purchase & 316 & 2.82 & 1.18 & -.15 & $.15^{* *}$ & .06 & $.26^{* *}$ & $.35^{* *}$ & & \\
7. Recommend & 316 & 2.87 & 1.27 & .15 & $.27^{* *}$ & -.03 & $.39^{* *}$ & $.37^{* *}$ & $.54^{* *}$ & \\
8. Resilience & 316 & 2.66 & 1.31 & .14 & $.10^{+}$ & -.05 & $.29^{* *}$ & $.23^{* *}$ & $.38^{* *}$ & $.42^{* *}$ \\
9. ATL & 316 & 3.96 & .83 & -.22 & -.04 & .04 & $.10^{*}$ & .08 & .04 & .05 \\
\hline
\end{tabular}

${ }^{* * *} \mathrm{p}<.01$

${ }^{*} p<.05$

$\mathrm{p}<.10$

${ }^{a}$ Correlations with perceived impact of initiative is based on the sample of participant consumers $(n=47)$. 
TABLE 4

UNSTANDARDIZED REGRESSION COEFFICIENTS FROM SUR REGRESSION

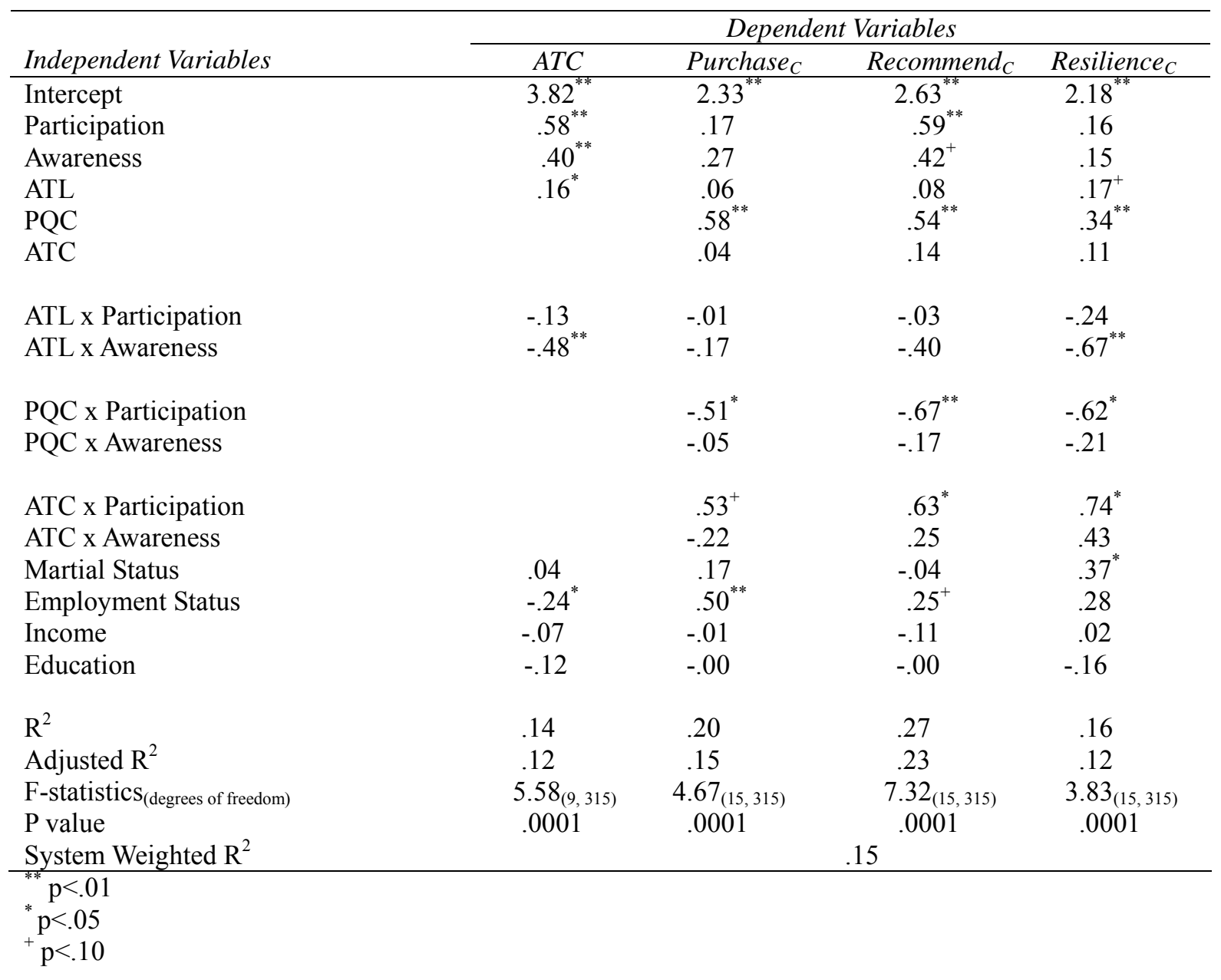




\section{APPENDIX}

\section{Pro-Challenger Behaviors}

Purchase $_{C}(1=$ never buy, $2=$ rarely buy, $3=$ sometimes buy, 4=often buy, $5=$ always buy)

How often do you buy [the challenger] when you shop for toothpaste for yourself?

Recommend $_{C}$ (1=not at all likely, $5=$ extremely likely)

In the next 6 months, how likely are you to recommend [the challenger] to someone you know?

Resilience $_{C}$ ( $1=$ definitely would not buy, $5=$ definitely would buy) If you heard or read a negative story about [the challenger], how would it affect your likelihood of buying [the challenger]?

Affective Trust in Challenger (ATC) (1=strongly disagree, $5=$ strongly agree)

The makers of [the challenger] have my best interests at heart

The makers of [the challenger] genuinely care about my family's well-being

Perceived Quality of Challenger (PQC) (1=strongly disagree, 5=strongly agree)

[The challenger] is good at whitening teeth

[The challenger] is good at freshening breath

Affective Trust in Leader (ATL) (1=strongly disagree, $5=$ strongly agree)

The makers of [the leader] have my best interests at heart

The makers of [the leader] genuinely care about my family's well-being

Perceived Impact of Initiative ${ }^{a}$ ( $1=$ strongly disagree, $5=$ strongly agree)

XX (the name of the initiative) has improved my child's life

XX (the name of the initiative) has enabled my child to take better care of his/her teeth

CSR Attributions $\quad(1=$ strongly disagree, $5=$ strongly agree $)$

Intrinsic attributions

The make of the challenger sponsors $\mathrm{xx}$ (the name of the initiative) because it genuinely cares about the well-being of children

\section{Extrinsic Attributions}

The make of the challenger sponsors $\mathrm{xx}$ (the name of the initiative) because it wants to sell more products to my community
Mean $=2.82$

$\mathrm{SD}=1.18$

Mean $=2.87$

$\mathrm{SD}=1.27$

Mean $=2.66$

$\mathrm{SD}=1.31$

$\mathrm{r}=.60$

mean $=3.77$

$\mathrm{SD}=.86$

$\mathrm{r}=.49$

Mean $=3.85$

$\mathrm{SD}=.80$

$\mathrm{r}=.61$

Mean $=3.96$

$\mathrm{SD}=.83$

$\mathrm{r}=.59$

Mean $=4.45$

$\mathrm{SD}=.58$

${ }^{a}$ Only participant consumers $(n=47)$ answered these questions. For all other variables, $n=316$. 





\section{Recent ESMT Working Papers}

ESMT No.

Corporate social responsibility and competitive advantage: Overcoming the trust barrier

10-006

C. B. Bhattacharya, ESMT

Pricing payment cards

10-005

Özlem Bedre-Defolie, ESMT

Emilio Calvano, Bocconi University

Profiting from technological capabilities: Technology commercialization strategy in a dynamic context

08-008 (R2)

Simon Wakeman, ESMT

Conditional cooperation: Evidence for the role of self-control

Peter Martinsson, University of Gothenburg

Kristian Ove R. Myrseth, ESMT

Conny Wollbrant, University of Gothenburg

Reconciling pro-social vs. selfish behavior: Evidence for the role of self control

Peter Martinsson, University of Gothenburg

Kristian Ove R. Myrseth, ESMT

Conny Wollbrant, University of Gothenburg

Estimating critical mass in the global cellular telephony market

08-004 (R1)

Michat Grajek, ESMT

Tobias Kretschmer, Ludwig-Maximilians-Universität München

Marketing social responsibility

Sumitro Banerjee, ESMT

Luc Wathieu, Ferrero Chair in International Marketing, ESMT

Quantification of harm in damages actions for antitrust infringements: Insights from German cartel cases

10-001

Hans W. Friederiszick, ESMT CA

Lars-Hendrik Röller, ESMT

A framework for monitoring relational quality in B2B technology partnerships

09-008

Francis Bidault, ESMT

Manfred Lüth, University of Nice

Olaf Plötner, ESMT

Enjoy! Assertive language and consumer compliance in (non)hedonic contexts

09-007

Ann Kronrod, Tel-Aviv University

Amir Grinstein, Ben-Gurion University of the Negev

Luc Wathieu, Ferrero Chair in International Marketing, ESMT

ISO 9000: New form of protectionism or common language in international trade?

09-006

Joseph A. Clougherty, University of Illinois at Urbana-Champaign

Michat Grajek, ESMT 


\section{ESMT}

European School of Management and Technology $\mathrm{GmbH}$

Schlossplatz 1

10178 Berlin

Germany

Phone: +49 (0)30212 31-1279

E-mail: publications@esmt.org

www.esmt.org 